\title{
Article
}

\section{Applying the Evaluation of Cultural Ecosystem Services in Landscape Architecture Design: Challenges and Opportunities}

\author{
Xin Cheng ${ }^{1, * \mathbb{D}}$, Sylvie Van Damme ${ }^{2}$ and Pieter Uyttenhove ${ }^{3}$ \\ 1 Department of Urban Planning and Landscape Architecture, Xihua University, Chengdu 610039, China \\ 2 School of Arts, University College Ghent, 9000 Ghent, Belgium; sylvie.vandamme@hogent.be \\ 3 Department of Architecture and Urban Planning, Ghent University, 9000 Ghent, Belgium; \\ pieter.uyttenhove@ugent.be \\ * Correspondence: xin.cheng@mail.xhu.edu.cn; Tel.: +86-159-0814-2467
}

Citation: Cheng, X.; Van Damme, S.;

Uyttenhove, P. Applying the

Evaluation of Cultural Ecosystem

Services in Landscape Architecture Design: Challenges and

Opportunities. Land 2021, 10, 665.

https://doi.org/10.3390/land10070665

Academic Editors: Alessio Russo and Giuseppe T. Cirella

Received: 18 May 2021

Accepted: 23 June 2021

Published: 24 June 2021

Publisher's Note: MDPI stays neutral with regard to jurisdictional claims in published maps and institutional affiliations.

Copyright: () 2021 by the authors. Licensee MDPI, Basel, Switzerland. This article is an open access article distributed under the terms and conditions of the Creative Commons Attribution (CC BY) license (https:// creativecommons.org/licenses/by/ $4.0 /)$.

\begin{abstract}
Landscape architects play a significant role in safeguarding urban landscapes and human well-being by means of design and they call for practical knowledge, skills, and methods to address increasing environmental pressure. Cultural ecosystem services (CES) are recognized as highly related to landscape architecture (LA) studies, and the outcomes of CES evaluations have the potential to support LA practice. However, few efforts have focused on systematically investigating CES in LA studies. Additionally, how CES evaluations are performed in LA studies is rarely researched. This study aims to identify the challenges and provide recommendations for applying CES evaluations to LA practice, focusing specifically on LA design. To conclude, three challenges are identified, namely a lack of consistent concepts (conceptual challenge); a lack of CES evaluation methods to inform designs (methodological challenge); and practical issues of transferring CES evaluations to LA design (practical challenge). Based on our findings, we highlight using CES as a common term to refer to socio-cultural values and encourage more CES evaluation methods to be developed and tested for LA design. In addition, we encourage more studies to explore the links of CES and landscape features and address other practical issues to better transfer CES evaluations onto LA designs.
\end{abstract}

Keywords: landscape architecture; cultural ecosystem services; design; evaluation

\section{Introduction}

Cities experience increasing environmental stress given the sharp rise of city populations, and the consequent loss and degradation of urban green spaces. Landscape architects therefore play a significant role in maintaining the human environment and well-being by planning, design, and management of urban landscapes more than ever [1]. The Council of Europe [2] defines landscape as an area that is perceived by people, and the character is the result of the action and interaction of natural or human factors. Landscape architecture (LA), as a profession, provides site planning, design, and management advice to improve the character, quality, and experience of the landscape [3]. Design is the core activity of the LA practice, considering many factors, such as the landscape itself, the intentions of the clients, the interaction of the users and the design setting, the materials, and the processes of creative expression. To do this effectively, landscape architects apply solid design processes and implementation methods, elaborated on and explained in an increasing amount of studies and publications on those topics. For example, Langley et al. [4] and Yue and Shao [5] summarize the core knowledge domains of LA, including the evolution of analytical methods for LA planning and design. Milburn and Brown [6] and Lenzholzer et al. [7] focus on incorporating research into the LA design process. Some scholars focus on new tools, such as Li and Milburn [8] and Gu et al. [9], who work on geodesign as a design tool.

LA primarily aims to organize the complexity of the landscape into comprehensible, productive, and beautiful places to improve the function, health, and experience of life. However, landscape architects increasingly face new challenges within today's rapid 
urbanization, such as designing resilient landscapes for adjusting to a changing climate and controlling natural disasters, creating a sense of place, and managing the growth of informal settlement $[10,11]$. Meanwhile, clients and the general public are no longer only interested in the aesthetic value of landscape but also increasingly concerned about ecological functions and environment conservation [12]. To achieve these multiple, oftencompeting objectives, landscape architects need a clear understanding of the relationships between humans and the environment and the interaction processes on how humans shape the landscape they rely on and experience. Hence, there is an urgent call for practical knowledge, skills, and methods to address these challenges within the LA profession [12].

The concept of ecosystem services (ES) refers to the benefits that people obtain from ecosystems [13]. They highlight the contributions that environments and landscapes provide for society and the economy and, more generally, for human well-being. They are divided into provisioning services, regulating services, supporting services, and cultural services [13]. In the last decade, several researchers conducted studies on integrating ES evaluation into spatial planning policies such as land use/cover to foster sustainable development. More recently, the relationship between ES and urban landscapes has also been increasingly investigated. The outcomes of ES evaluations are recognized to have the potential to support practical application and decision-making [14-19]. Among ES, cultural ecosystem services (CES), namely the non-material benefits that people get from ecosystems, are regarded as directly influencing human-wellbeing and having the potential to motivate people's willingness to protect urban greens $[14,20]$. Whether or not people are familiar with the term, the concept resonates with nearly every human being, such as the experience of recreational activities and scenery appreciations. Although different definitions have been developed so far, CES are generally defined as the non-material benefits people obtain from ecosystems [13], which was adopted by this study. CES evaluation is one of the biggest challenges for further applying in practice. Evaluating what people obtain is a concise way of disseminating the importance of ecosystems or landscapes [14]. Various evaluation methods have been developed and they can generally be classified into monetary methods and non-monetary methods, depending on whether the evaluation outcomes are expressed by money or not [14]. The classification can be further divided into revealed preference and stated preference methods. The revealed preference method means observing the actual markets or human behaviors related to the CES to assess CES. The stated preference method means directly asking about one's values to assess CES [14]. CES evaluation studies and LA studies share many commonalities. First, they focus on the "human dimension" of landscapes [21]. For example, LA has long been concerned with questions of the human perception of and involvement with nature. Meanwhile, CES evaluations heavily depend on people's perceptions and preferences. Second, both have a broad knowledge about the assessment of aesthetic values, place identity, and cultural heritage on-site and in specific contexts [21]. Landscape architects may not be familiar with ES or CES; however, they are familiar with concepts such as aesthetics or heritage [22]. Third, both highlight the local scale of different landscape types, especially while studying urban green spaces like urban parks, gardens, and forests, and, fourth, both are concerned with the benefits provided by landscape features that can enhance the quality of the landscapes and the entire system [23]. For example, parks are recognized as providing a range of CES, and, in many areas, these relate to scientifically-assessed landscape features, such as the proportion of vegetation [24] Similarly, De Valck et al. [25] test the different degrees of high or low vegetation that indicate outdoor recreation.

CES are highly related to LA studies, and the outcomes of CES evaluations have the potential to guide LA practices. Although they share many commonalities, few efforts have focused on systematically investigating CES in LA studies. Additionally, how CES evaluations are performed in LA studies is rarely investigated. This paper aims to identify the challenges and opportunities of integrating CES evaluations into LA designs. Specifically, it discusses the problems and challenges of existing studies, the examined CES categories, the 
implications and applications of evaluation methods, the links between CES and landscape features, and opportunities for future study.

With this in mind, we specifically ask which CES are studied, what evaluation methods are used, and how CES are connected to landscape features in LA studies. To achieve this, we focus on three areas:

1. First, we focus on the existing publications about CES within LA studies through bibliographic research. Looking at the existing publications from a scientific database helps with understanding the status quo of the CES in LA studies. This approach allows for investigating a topic comprehensively and covering a large timespan [26].

2. Second, we focus on how landscape architects express their ideas in design proposals related to CES through a systematic review of design proposals. Design proposals differ in scale and complexity. They involve various constituent elements for a variety of purposes and scales. They are often used to present design outcomes and communicate with clients. Focusing on the design proposals helps with understanding why CES are important, and how the abstract CES are expressed by the physical landscape features, according to designers.

3. Third, we focus on how landscape architects state their ideas and values related to CES through interviews. Not all of the information is shown in design proposals. The design process is complex, and the mechanisms behind the designs are unknown. Moreover, more practical issues can only be revealed by interviewing the designers as dealing with those issues is one of their daily tasks. Hence, we interviewed landscape architects directly to reveal more detailed information that might be missed, to reveal the real thoughts of designers and to get the primary data for further analysis.

Combining these three methods provided a comprehensive knowledge of CES evaluation in LA fields. In addition, this study focused on urban parks in China. As an important component of urban green spaces, urban parks are crucial for securing human well-being by providing diverse benefits, and they have been studied by ES and LA fields. Urban parks are important indicators used to estimate the quality of life in a city. Moreover, studying urban parks is vitally important for their design, planning, and management, especially in the case of China, which is experiencing increasing social and environmental pressure caused by the rapid population growth in cities. Hence, it is an urgent call for valuable tools to aid urban park design.

\section{Methods}

We combined three methods to investigate the challenges and opportunities of applying CES evaluations in LA studies. Table 1 shows the study process. Specifically, we first reviewed existing scientific articles to have a general overview of the research on urban parks and identify items related to CES and the links between these terms. Then, we conducted a systematic review of selected park proposals based on a guideline (Table A1 in Appendix A). Subsequently, we interviewed landscape architects directly to know their thoughts about CES evaluations and other practical issues (Table A2).

Table 1. Overview of the study process.

\begin{tabular}{ccc}
\hline Study Process & Data Collection & Data Analysis \\
\hline (1) Review journal articles, dissertations, and conference papers from CNKI database & 5273 publications & Quantitative \\
(2) Systematic review of park proposals & 83 proposals & Quantitative \\
(3) Interviews of landscape architects & 12 interviewees & Qualitative \\
\hline
\end{tabular}

CNKI is a key national information and knowledge database that includes journals, doctoral dissertations, master's theses, proceedings, newspapers, yearbooks, statistical yearbooks, patents, standards, etc. in China.

\subsection{Review of Keywords and Abstract of Scientific Publications}

To review the existing publications about CES within LA studies, we used key terms and phrases based on reviewing the abstracts and keywords of scientific publications. This technique can be used to quantify a large sample $[26,27]$. We first searched "landscape 
architecture design" and "urban park" in the China National Knowledge Infrastructure (CNKI) database, including journals, dissertations, and conference papers. We set the timespan up to November 2019, which resulted in 5273 items. Then, we screened the key terms using CiteSpace.5.5.R2 (parameter settings: Years Per Slice: 2; Node Types: Keyword). The frequency of the keywords could reflect hot topics and core content over a set period [28]. Subsequently, we counted the occurrence frequency of key terms in relation to CES. There are different definitions and classifications of CES, and different authors use different terms based on their study focus. Here, we recorded the terms that the authors reported. Finally, other terms were also presented and counted if they were linked to CES terms.

\subsection{Review of Design Proposals}

A systematic review was conducted to review the design proposals of urban parks in China. More specifically, we first collected park proposals from LA companies, government agents, and internet searches. A balance of park types and scales were also noticed, and, finally obtained, 83 items were obtained. Second, we asked a set of questions when we reviewed each park proposal and recorded the answers (Table A1), including the time, park scales, park types, CES types, evaluation methods, and the relationships with landscape features. More specifically, we set the classification of the answers of identified proposals as shown in Table 2. There are several different classification mechanisms of urban parks, and it is beyond the scope of this study to give a comprehensive account of the various classifications. In this study, we based on the Standard for Classification of Urban Green Space of China.

Table 2. Review of design proposals.

\begin{tabular}{|c|c|}
\hline Question Categories & Answer Descriptions \\
\hline (1) Time & The year the design proposal came out. \\
\hline (2) Scale & The size of the park. \\
\hline (3) Type & $\begin{array}{l}\text { The urban park was classified into four major categories: } \\
\text { comprehensive park, community park, topic park (children's park, the } \\
\text { cultural relics park, the commemorative park, zoological garden, sports } \\
\text { park, etc.), and belt-shaped park. Among them, comprehensive parks } \\
\text { include a large area of green land and numerous public service } \\
\text { facilities, which are the main locations for residents to recreate, and a } \\
\text { significant public open space [29]. }\end{array}$ \\
\hline (4) CES types & $\begin{array}{c}\text { We identified CES types by focusing on the non-material characteristics, } \\
\text { meaning there was no pre-set classification before reviewing each } \\
\text { proposal. We recorded the original terms that authors reported in } \\
\text { proposals and similar terms were grouped. }\end{array}$ \\
\hline (5) Evaluation of CES methods & $\begin{array}{l}\text { We recorded if the designers introduced CES evaluation methods in } \\
\text { their design proposals. }\end{array}$ \\
\hline $\begin{array}{l}\text { (6) The relationships with other landscape } \\
\text { elements/features (vegetation, benches, etc.) }\end{array}$ & $\begin{array}{l}\text { The classifications of characteristics were selected from the literature } \\
\text { that focused on the park characteristics, including Bertram and } \\
\text { Rehdanz [30], Campbell et al. [31], Chiesura [32], and Hegetschweiler } \\
\text { et al. [33]. Based on this classification, we recorded and grouped the } \\
\text { terms that the authors reported in their designs. For the detailed types, } \\
\text { see Table A1. }\end{array}$ \\
\hline
\end{tabular}

\subsection{Interviews of Landscape Architects}

To reveal more detailed information from designers, 12 semi-structured phone interviews were conducted between November, 2019 and January, 2020. The interviewees were landscape architects with rich experience in park design in China and consisted of three groups. The first group consisted of designers in the government's LA design institute. The second group was made up of professors working at the university who were also 
doing LA projects, and the third group contained landscape architects from LA design companies. The interview started with a brief description of this study. Subsequently, a set of questions was asked based on guidelines that directed towards our research questions (Table A2). The interviewees were prompted with a talk-generating question, and the structure of the interview was adjusted to their statements. Each interview was conducted over 30 to $90 \mathrm{~min}$, depending on the interviewee's interests and schedule. In addition, the results were qualitatively analyzed according to the research goals. For the presentation of our results, quotations were translated from Chinese to English. The interview texts were summarized when interviewees shared the same ideas. The individual ideas were recorded independently.

\section{Results}

\subsection{CES in Scientific Publications}

This section presents the high-frequency keywords assigned by the CNKI database. A minimum of two occurrences of each keyword was included in the network, resulting in 208 keywords and 1266 links. Notably, we merged similar terms, because the original language was Chinese, and some terms share the same meaning, and the final results contained 30 keywords (Table 3). Specifically, the results revealed that regional/local culture (frequency $=212$ ), humanization/user-friendly (85), and cultural characteristic (70) were mentioned far more than other keywords. Other high-frequency keywords included historical culture (16), urban culture (9), theme culture (8), leisure and recreation (8), and place spirit (5). All of these keywords served as a reference point for finding and understanding the possibilities of applying CES in the landscape design of urban parks.

Table 3. List of keywords in relation to CES.

\begin{tabular}{cccc}
\hline Keyword & Frequency & Keyword & Frequency \\
\hline Regional/local culture & 212 & Expression & 4 \\
Humanization-/user-friendly & 85 & Experience & 4 \\
Culture characteristic & 70 & Art & 4 \\
Historical culture & 16 & Creative & 3 \\
Urban culture & 9 & Nature education & 3 \\
Theme culture & 8 & Urban characteristic & 2 \\
Leisure and recreation & 8 & Culture heritage & 2 \\
Place spirit & 5 & Social life & 2 \\
Ecological aesthetic & 4 & Tradition & 2 \\
\hline
\end{tabular}

In addition, the intensity of the link between two keywords was computed based on the number of times they were mentioned together. Sixty-three keywords were found linked to the CES keywords (Table A3). The main connecting keywords were landscape architecture design (23), landscape architecture (23), urban park (18), theme park (11), and ecology (8). The first three keywords were expected as they were our search terms. Other highly linked keywords included design (7), plant design (7), local culture (7), urban culture (6), historical culture (6), waterfront landscape (6), landscape renovation (5), humanization/user-friendly (5), urban wetland park (5), and comprehensive park (5). Other items, such as sculpture, environmental infrastructure, and plant community, were related to landscape features. There were surprisingly no terms directly about evaluation or evaluation methods.

\subsection{CES in Park Proposal}

The sizes of the 83 reviewed parks ranged from 2.5 ha to 1500 ha between 2003 and 2019. The parks included 31 comprehensive parks, 37 topic parks, 7 community parks, and 8 belt-shaped parks (Figure 1). Topic parks included the wetland park (6), the sports park (6), the expo park (5), the children's park (3), the water park (3), the amusement park (2), the botanical garden (2), the shopping park (2), the ecological park (2), the cultural 
park(2), the lake park (1), the cultural relics park (1), the commemorative park (1), and the zoological garden (1).

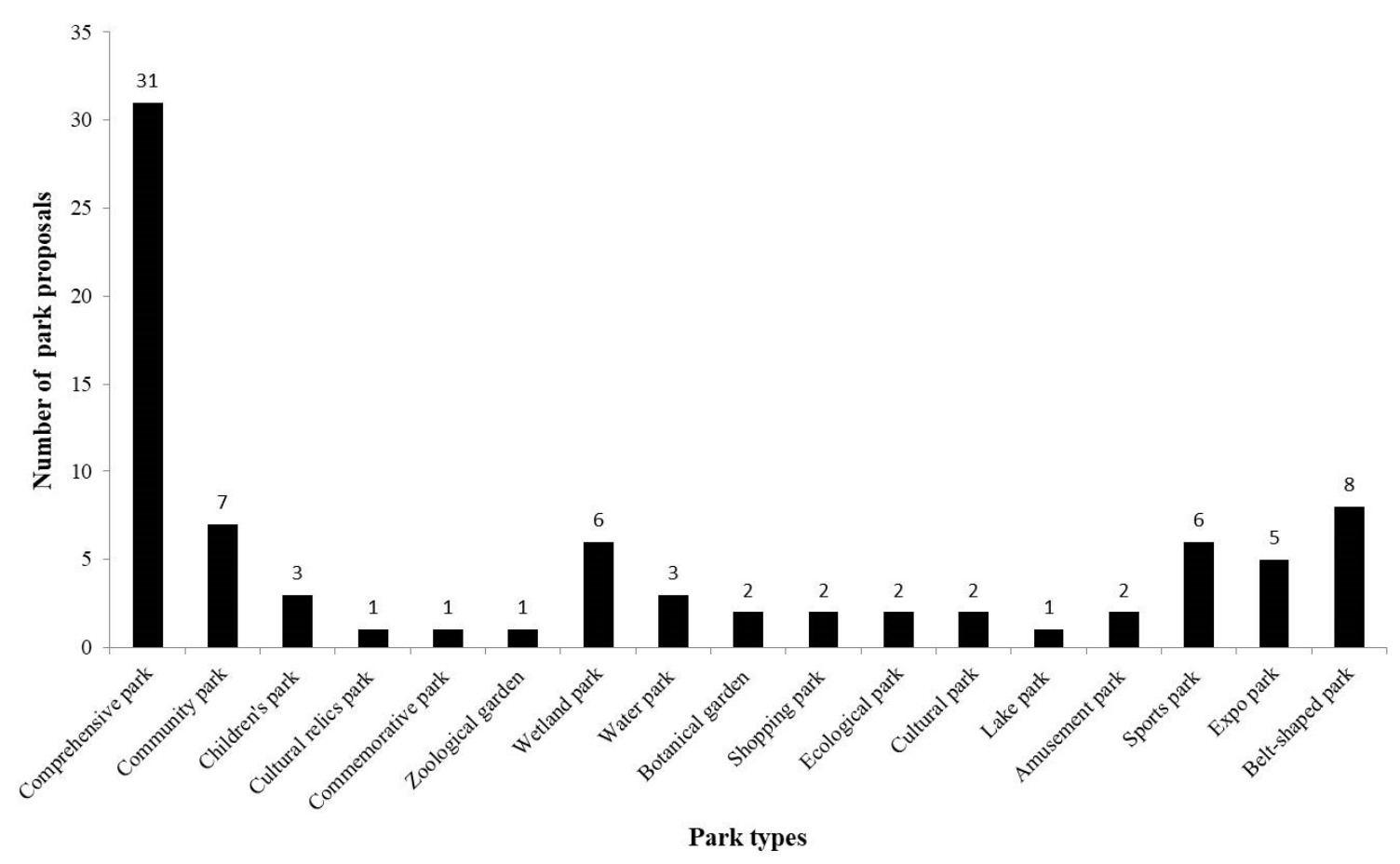

Figure 1. The types of the park.

The concept of CES was not found in park proposals, but 50 terms were identified in relation to CES (Table 4). The most mentioned types were recreation (73), education (26), and aesthetic (13), followed by traditional culture (12), sense of place (11), social interaction (10), history (8), Shan-Shui culture (8), sense of nature (7), art (7), tourism (6), and experience (6). Recreation included walking, running, boating, fishing, biking, bird watching, tea dinking, flower watching, farming, bird watching, fishing, skating, etc.

The majority of proposals (74) mentioned that they used a document research approach through analyzing materials such as landform, existing information and data, and master plan. Among them, 56 proposals analyzed successful case studies in China and other countries. Twelve proposals stated that they conducted field surveys, and four used questionnaires to ask people how they perceived the existing parks and what they liked.

Landscape features were wildly used to link CES to designs, and 26 features were found in proposals (Table A4). Plants (41) were the most mentioned feature in park proposals, followed by architecture (28), playground (26), sculpture (21), and sports-/ fitness facilities (20). Other features, such as signs (19), furniture (12), recreation facilities (10), path (9), water (8), and landform (7), were also mentioned often.

\subsection{CES in the View of Landscape Architects}

Three interviewees who were also involved in landscape education in a university stated that they knew the concept of CES, but they had not used it in their designs. The other interviewees stated this was the first time to hear about this concept. However, the landscape architects were familiar with related terms, such as socio-cultural value. They stated that it is essential that parks are designed for recreation, aesthetics, and education purposes. They agreed on the importance of socio-cultural values and non-material benefits in LA designs. However, they also stated that it is difficult to be aware of them and capture them because of their abstract and intangible characteristics, which often depend on designer's experience, values, and preferences. 
Table 4. CES categories in park proposals.

\begin{tabular}{cccc}
\hline CES Category & Number & CES Category & Number \\
\hline Ethnic culture & 1 & Spiritual & 4 \\
Education & 26 & knowledge & 1 \\
Recreation & 73 & Tourism & 6 \\
Spiritual and religious value & 3 & Shopping experience & 1 \\
Cultural diversity & 3 & Identity & 3 \\
Traditional culture & 12 & Respect of nature & 1 \\
History & 8 & Love & 2 \\
Sense of nature & 7 & Traditional philosophy & 1 \\
Life style & 1 & Peace & 1 \\
Local culture & 3 & Agricultural culture & 3 \\
Experience & 6 & Cultural interaction & 1 \\
Sense of place & 11 & Fairy tale & 1 \\
Social interaction & 10 & Tranquil & 1 \\
Social equity & 1 & Human friendly & 1 \\
Folk culture & 5 & Historical celebrities & 1 \\
Memory & 1 & Local identity & 1 \\
Aesthetic & 13 & Commerce culture & 1 \\
Art & 7 & Local connection & 1 \\
Patriotism & 1 & Industry culture & 1 \\
Cultural heritage & 2 & Surname culture & 1 \\
Celebrity culture & 1 & Minority culture & 1 \\
Food culture & 3 & Ancient drama culture & 1 \\
Social relations & 5 & Ancient architecture & 1 \\
Shan-Shui culture & 8 & culture & 1 \\
Health & 2 & Adventure & 1 \\
\hline & & &
\end{tabular}

On the one hand, landscape architects recognized the huge potential of CES evaluations to support their practices. They claimed that it may help them capture cultural benefits and better understand human and environmental processes and further integrate them into the ES framework to achieve multifunctional landscapes, not single-function landscapes. Designers stated that it is difficult to find an overarching value that would allow aesthetic, social, economic, and environmental values to be measured against one another [34]. Moreover, it should be a useful tool to communicate with clients and stakeholders by showing them potential benefits. One designer stated, "It's very important for communicating with clients who make the final choice. Therefore, you're actually selling your ideas to them and somehow persuade them to trust your designs. So more supporting proofs are needed to strengthen your design plans."

However, designers also stated that there are still many issues to be addressed. The biggest challenges are the methodological and practical issues. For example, the interviewees asked series of questions: "when do I need to evaluate CES and in which stages (before design, during design, or after design)?" "What methods do I need, and how?" "What kind of expertise is needed for this?" "Do I need CES experts to aid me?" "Who is involved in this evaluation, and how can it be facilitated?" "What is the difference when dealing with different parks of different scales? For example, the design of children parks is totally different from the zoological garden." "Does it influence the designer's creative expression or artistry?"

When asked how they transfer the CES to their designs, designers stated that recreation, aesthetics, or educational values are easier to express. For example, recreational values are often expressed by creating spaces for recreation and equipping them with recreational facilities. As for the other more abstract CES, designers stated that they are often inspired by history, a story, a culture, or a celebrity, and they often use physical landscape features to create the cultural atmosphere. For example, Shan-Shui culture was highlighted by interviewees; one stated, "Shan-Shui refers to mountains and rivers and broadly refers to nature in general, which is an important source of inspiration for creating 
places." Another example is the use of plants: "Bamboo, for example, is often used in designs to emphasize the elegance of the environment because, in Chinese culture, it is a symbol representing the character of moral integrity, modesty, and loyalty." Sculptures are also widely used to commemorate a celebrity or historical event or person. Designers also stated that the process is complex and depends on sites and specific contexts.

\section{Discussion: Challenges and Opportunities}

This study focuses on which CES are studied, what evaluation methods are used, and how the concepts connected to physical landscape featured in LA studies. In this section, we highlight three key challenges based on our findings and further discuss opportunities for landscape architects to contribute to apply CES evaluations into LA studies in the future.

\subsection{Conceptual Challenges: A Lack of Consistent Concepts}

Although the term CES was not been used, various socio-cultural values were found in the LA publications and design proposals. Local culture and historical culture were widely highlighted, benefiting from the fruitful history and culture of China. Landscape architects did not use the term CES because the concept of CES is relatively new, proposed in recent decades. Chinese scholars seemed to be unaware of this progress until recent years, and the number of studies focusing particularly on CES is still very limited [35]. In addition, some interviewees stated that they are unaware of the latest research trends or methods because they do not read international research publications as their English is poor. Another landscape architect stated that both CES and other terms he often uses such as historical culture or Shan-Shui culture all refer to the social-cultural values, so it does not matter whether he uses the term CES or not. The landscape architects also highlighted that the key is how to evaluate them and use them to guide the LA design practice.

Although CES have a range of definitions based on diverging views, leading to alternative classification schemes, they are generally described as socio-cultural values or non-material benefits. There are several mainstream classifications of CES in ES studies, such as the Millennium Ecosystem Assessment classification, Economics of Ecosystems and Biodiversity, Common International Classification of Ecosystem Services, Final Ecosystem Goods and Services Classification System, and, more recently, the Intergovernmental Platform on Biodiversity and Ecosystem Services. Diverse classifications were developed to clarify CES, and they are still in progress [36,37]. However, a consistent concept is necessary as this gives an opportunity to organize a dialogue and cooperation between LA and CES studies [21]. CES have the potential to be a common term referring to sociocultural benefits. The results show that many CES are referenced and studied in LA research and design proposals but not by explicitly using the term CES. Hence, an opportunity is missed by not highlighting the link between the environment and humans that implicitly exists within the research and proposals. Given that this anthropocentric rationale can be effective at generating support for environmental conservation [38], the explicit inclusion of the CES concept may also lead to better ecosystem protection in general [39]. Moreover, practitioners who lack basic knowledge about CES concepts may be less aware of what could benefit from their designs. Hence, the inclusion of a common term, concept, or definition for CES in the LA studies and design proposals and other similar documents is needed to promote LA practice. Furthermore, the existing CES evaluation studies by many other countries and their various methods and indicators can inspire LA studies in China. However, a concern about the use of CES evaluations by designers is that the application of CES as a scientific concept might cause a loss of creativity and artistic thinking. It is a challenge for designers to balance the evaluation and creativity, which requires designers to have a full understanding of the knowledge of CES and LA design.

\subsection{Methodological Challenges: Lack of Evaluation Methods to Inform Designs}

Most design proposals use document research, followed by questionnaires which are based on people's preferences and perceptions. In reality, expert-based methods are the 
most used, even when this is not mentioned in the proposals. Indeed, the designs highly depend on the experiences, skills, and values of the designers as experts, and evidencebased design is widely used for LA designs in China. An evidence-based design highlights the process of design by critically and appropriately integrating various aspects, such as credible data, practitioner design expertise, client needs, and resources, in order to achieve project objectives [40]. Although evidence-based design has been widely used, it has been simultaneously critiqued for rigidity and misapplication in China. Hence, landscape architects gravitate to the support of research by integrating "research-informed design" as a broader term with concepts, fields, tools, or methods to support their practice. In this study, CES is regarded as a research tool that has the potential to aid LA practices. It is clear that, although CES are difficult to evaluate, a systematic evaluation of CES could guide the designers to capture and maximize them.

The diversity of CES study methods provides a rich inventory for scholars to assess CES. Instruments for assessing CES, including quantification, valuing, mapping, and modeling, are increasingly studied in CES and ES research. Many evaluation methods provide an opportunity to evaluate CES in LA studies. The evaluation methods are generally divided into monetary and non-monetary methods or revealed preference and stated preference methods as introduced in the first section. Cheng et al. [14]; Hirons et al. [41]; and Spangenberg and Settele [42] summarize the evaluation methods. In urban green space studies, non-monetary methods were used more, especially questionnaires and interviews, which emphasize the preferences and perceptions of people. It highlights the importance of the role that humans play in interaction with landscapes. Participatory mapping can be used to evaluate the crucial locations and settings for an urban park. Such assessments can provide valuable information for designers to increase CES provisions in the urban landscape. A social media-based method was used to reveal people's preference of CES based on the social media data from various resources such as Flickr or Instagram. Monetary methods, such as willingness to pay (WTP), can be used to know people's preferences for specific park settings. Both monetary and non-monetary methods and their combinations are encouraged to be used in LA studies. To achieve this, combing economics with other disciplines such as social or behavioral sciences is significant to know how to shift human aspects to environment setting, which is encouraged in future studies.

\subsection{Practical Challenges: Practical Issues of Transferring CES to LA Design}

In addition to the conceptual and methodological challenges, there are also more practical issues. They are: the relationships between CES and landscape features, the evaluation scopes (i.e., park types and size), data collection, and operation.

\subsubsection{CES and Landscape Features}

CES are highly related to landscape features. Sculpture, environmental infrastructure, and plant community were identified in the publications review. In addition, plants, architecture, playground, sculpture, and sports-/fitness facilities were the features used most to indicate CES in the reviewed design proposals. Landscape architects also highlighted the importance of the landscape features to express their ideas about CES. Linking the CES to physical landscape features is regarded as an efficient way to ground the abstract concept into the designs. The link between CES and landscape features provided an opportunity to help designers easily grasp CES and create essential links between ecosystem processes and management actions [43]. For example, some studies have tried to link CES to a location by means of participatory mapping, which allows people to mark the sites of CES (see Brown and Hausner [44]; Bryan et al. [45]; and Plieninger et al. [46]). Such studies provide designers with insight into the location of CES supplies and their correlations with specific features [30]. De Valck et al. [25] test the influence of different degrees of high or low vegetation on recreation and how such specific connections have the potential to support the vegetation design and landscape management. Benches are also regarded as an indicator of aesthetic values that can guide LA designs [47]. However, the number 
of studies linking CES and landscape features are still limited, and future studies should focus more on the links between CES and landscape features to guide LA designs.

\subsubsection{Scopes, Data Collection, and Implementation}

Many other factors influence the transfer of the concept of CES into LA design. The design process is complicated, and landscape architects need to coordinate a series of tasks to be performed by a number of people over a set period. They need to consider factors such as scale, types, layout, and features and organize the landscape to create a functional, comprehensible, and beautiful place. In addition, landscape architects need to consider the data collection and operation process when integrating CES evaluation into this process.

Specifically, the first issue is the evaluation scope including park scales and types. Parks with different types and scales have different expressions. For instance, sports parks emphasize recreation more than commemorative parks, which highlight spiritual values as stated by designers, and, in this case, landscape architects often have to trade off different CES. Meanwhile, different parks with different sizes add complexity. Hence, defining types and scales is crucial at the beginning to clarify the study scope and further select evaluation methods.

The second issue is how to collect the data. Data collection is significant to support practices, and depends on what methods are selected. The data can be divided into primary data or secondary data and quantitative data or qualitative data. For example, LA designs often depend on the secondary data derived from the document research, and primary data derived from the interviews. The primary data often engage stakeholders because CES evaluation is recognized to rely heavily on people's preferences and perceptions. LA is a user-inspired and user-useful discipline that requires designers to achieve the requirements of the clients and collaborate with them, making it more complex. CES evaluation could contribute to the increased congruence between different stakeholders. It is a useful tool for communicating with clients by showing what benefits they can have based on design proposals.

The third issue is the operation of the CES evaluation, such as who is involved in the evaluation and how it can be implemented. There is often a lack of local research capacity to undertake valuation research [48], which requires designers to have the capacity to act as enumerators or facilitators. As most designers do not know about CES, training on how to evaluate CES is essential for designers. Additionally, the development of evaluation methods, toolboxes, and practical guidelines is important to aid designers. Meanwhile, cooperation with ecologists or other experts is also highly encouraged at the beginning.

We take account of the complexity of practical issues and emphasize that there is not one simple and straightforward way to address practical issues. This study presented assumptions and discussions for tackling the complexity of involving CES evaluation in landscape design.

\section{Conclusions}

Landscape architects are facing increasing pressure due to rapid urbanization and call for practical knowledge, skills, and methods, etc. to support their designs. This study proposes that the concept of CES could have the potential to address their pressures by integrating CES evaluation in LA designs. This study identified three challenges, including consistent concepts, methods for evaluating CES, and practical issues of transferring CES to LA design. We further provided recommendations about how to deal with these challenges by highlighting opportunities for designers to contribute to LA and CES research in the future. (1) We highlighted developing consistent concepts and highlighted using CES as a common term to refer to socio-cultural values. (2) We encouraged using more evaluation methods to assess CES in LA studies, including monetary and non-monetary methods, such as WTP, participatory mapping, and the social media-based method. In addition, (3) we encouraged more studies addressing various practical issues to better guide LA designs. The first issue is to define park types and scales, which is crucial at the beginning 
to clarify the study scope and further select evaluation methods. The second issue is to collect data, especially the primary data that are often ignored in LA studies. The third issue is to develop evaluation methods, toolboxes, and practical guidelines to aid designers. In addition, training on how to evaluate CES is also essential for designers.

Author Contributions: X.C.: Conceptualization, Methodology, Investigation, Formal analysis, Writing-Original draft preparation. S.V.D.: Methodology, Writing—Reviewing and Editing. P.U.: Writing-Reviewing and Editing. All authors have read and agreed to the published version of the manuscript.

Funding: This research was funded by The Talent Introduction Program of Xihua University.

Institutional Review Board Statement: Not applicable.

Informed Consent Statement: Not applicable.

Data Availability Statement: The data presented in this study are contained within this article.

Conflicts of Interest: We declare that we have no conflicts of interest to this work. We have no financial and personal relationships with other people or organizations that can inappropriately influence our work.

\section{Appendix A. Supplementary Data}

This appendix contains four tables.

Table A1. Set of questions asked for every design proposal reviewed.

\begin{tabular}{|c|c|}
\hline Question & Response Categories \\
\hline \multicolumn{2}{|l|}{ (1) Year } \\
\hline (2) Park types & $\begin{array}{l}\text { Comprehensiveness park, community park, topic park (children's park, } \\
\text { the cultural relics park, the commemorative park, the zoological garden, } \\
\text { and the botanical garden, etc.), and belt-shaped park. }\end{array}$ \\
\hline (3) Park scale & Size \\
\hline (4) In relation to CES categories & $\begin{array}{c}\text { Cultural diversity, spiritual and religious values, knowledge systems, } \\
\text { educational values, inspiration, aesthetic values, social relations, } \\
\text { recreation and ecotourism, cultural heritage values, and sense of place, } \\
\text { etc. }\end{array}$ \\
\hline (5) Evaluation methods & Yes/No \\
\hline If yes, what? & $\begin{array}{c}\text { Document research, questionnaires, and interviews, etc. } \\
\text { Yes/No }\end{array}$ \\
\hline $\begin{array}{l}\text { (6) In relation to landscape features } \\
\text { If yes, what? }\end{array}$ & $\begin{array}{l}\text { Landform, plant, recreation facilities (camping, picnic, BBQ, Bird/fish } \\
\text { feeder, birdbath, bird box, etc.); water, architecture, benches, sculptures, } \\
\text { etc. }\end{array}$ \\
\hline
\end{tabular}

Table A2. Example of interview guidelines.

\begin{tabular}{ccc}
\hline Interviewer: & Date (MM/DD/YYYY): & Start Time: \\
\hline Interviewee: & Park once involved: \\
\hline Q1. \\
Have you ever heard about the concept of CES, ES, or services, etc.? If yes, how do you think about this concept? If no, the \\
interviewers will explain the concept to interviewees.
\end{tabular}

Q2.

Do you mention CES/ social cultural values (aesthetic values, recreation, etc.) in your park designs? How? Could you give me some examples?

If no, why?

Q3.

What challenges can you imagine for transferring CES into your design? 
The interview begins with an informed consent about the recording and an explanation about the confidentiality of the interview. Following is a rough and easy to understand description of the aim of our study.

Table A3. Keywords link to CES.

\begin{tabular}{ccccc}
\hline Keyword & Frequency & Keyword & Frequency & Keyword \\
\hline landscape architecture design & 23 & forest park & 2 & Frequency \\
landscape architecture & 23 & urban & 2 & protection \\
urban park & 18 & environmental & 2 & renew \\
infrastructure & function & 2 & sustainable development \\
ecology & 11 & geology park & 2 & community park \\
plant design & 8 & old people & 2 & mountain park \\
design & 7 & ecological design & 2 & rural landscape \\
local culture & 7 & development & 2 & country park \\
historical culture & 7 & place/cite/space & 2 & design point \\
waterfront Landscape & 6 & landscape development & 2 & expression \\
humanization/user-friendly & 5 & ecological landscape & 2 & ecological restoration \\
urban wetland park & 5 & leisure and recreation & 2 & creative \\
landscape renovation & 5 & integrate & 2 & exemplary \\
comprehensive park & 5 & recreational space & 2 & environment \\
nature & 4 & urban culture & 1 & design principle \\
urban green & 4 & urbanization & 1 & 1 \\
open space & 4 & park design & 1 & 1 \\
culture & 4 & point, line, and surface & 1 & urban design \\
design strategy & 3 & characteristic & 1 & recreational behavior \\
wetland & 3 & application & 1 & influence
\end{tabular}

Table A4. Landscape feature categories in park proposals.

\begin{tabular}{cccccc}
\hline Code & Category & Number & Code & Category & Number \\
\hline 1 & Plants & 41 & 14 & Bridge & 4 \\
2 & Architecture & 28 & 15 & Bench & 5 \\
3 & Playground & 26 & 16 & Market square & 2 \\
4 & Sculpture & 21 & 17 & Children playground & 2 \\
5 & Sports- / fitness facilities & 20 & 18 & Lawn & 2 \\
6 & Signs & 19 & 19 & Local stone & 2 \\
7 & Furniture & 12 & 20 & Fountain & 1 \\
8 & Recreation facilities & 10 & 21 & Camping facilities & 1 \\
9 & Path & 9 & 22 & Shopping street & 1 \\
10 & Water & 8 & 23 & Stores & 1 \\
11 & Landform & 7 & 24 & Liewing platform & 1 \\
12 & Lighting & 5 & 25 & Watch tower & 1 \\
13 & Tower & 5 & 26 & &
\end{tabular}

\section{References}

1. Chen, X.; Wu, J. Sustainable landscape architecture: Implications of the Chinese philosophy of "unity of man with nature" and beyond. Landsc. Ecol. 2009, 24, 1015-1026. [CrossRef]

2. European Landscape Convention; Report and Convention; Council of Europe: Strasbourg, France, 2000.

3. Deveikienè, V. Methodological guidelines for optimizing the interaction between landscape architecture and urban planning. Sci. J. Latv. Univ. Life Sci. Technol. Landsc. Archit. Art 2018, 12, 7-21. [CrossRef]

4. Langley, W.N.; Corry, R.C.; Brown, R.D. Core Knowledge Domains of Landscape Architecture. Landsc. J. 2018, 37, 9-21. [CrossRef]

5. Yue, B.-R.; Shao, S.-L. The evolution and trends of analytical methods for landscape planning and design. J. Xi'an Univ. Archit. Technol. Nat. Sci. Ed. 2010, 42, 690-695. 
6. Milburn, L.-A.S.; Brown, R.D. The relationship between research and design in landscape architecture. Landsc. Urban Plan. 2003, 64, 47-66. [CrossRef]

7. Lenzholzer, S.; Duchhart, I.; Koh, J. ‘Research through designing'in landscape architecture. Landsc. Urban Plan. 2013, 113, 120-127. [CrossRef]

8. Li, W.; Milburn, L.-A. The evolution of geodesign as a design and planning tool. Landsc. Urban Plan. 2016, 156, 5-8. [CrossRef]

9. Gu, Y.; Deal, B.; Larsen, L. Geodesign processes and ecological systems thinking in a coupled human-environment context: An integrated framework for landscape architecture. Sustainability 2018, 10, 3306. [CrossRef]

10. Alizadeh, B.; Hitchmough, J. A review of urban landscape adaptation to the challenge of climate change. Int. J. Clim. Chang. Strateg. Manag. 2019, 11, 178-194. [CrossRef]

11. Steiner, F. Frontiers in urban ecological design and planning research. Landsc. Urban Plan. 2014, 125, 304-311. [CrossRef]

12. Grose, M.; Frisby, M. Mixing ecological science into landscape architecture. Front. Ecol. Environ. 2019, 17, 296-297. [CrossRef]

13. MEA. Millennium Ecosystem Assessment: Ecosystems and Human Well-being: Synthesis; Island Press: Washington, DC, USA, 2005.

14. Cheng, X.; Van Damme, S.; Li, L.; Uyttenhove, P. Evaluation of cultural ecosystem services: A review of methods. Ecosyst. Serv. 2019, 37, 100925. [CrossRef]

15. De Groot, R. Function-analysis and valuation as a tool to assess land use conflicts in planning for sustainable, multi-functional landscapes. Landsc. Urban Plan. 2006, 75, 175-186. [CrossRef]

16. De Groot, R.; Hein, L. Concept and Valuation of Landscape Functions at Different Scales, in Multifunctional Land Use; Springer: Berlin/Heidelberg, Germany, 2007; pp. 15-36.

17. Lautenbach, S.; Kugel, C.; Lausch, A.; Seppelt, R. Analysis of historic changes in regional ecosystem service provisioning using land use data. Ecol. Indic. 2011, 11, 676-687. [CrossRef]

18. Maes, J.; Egoh, B.; Willemen, L.; Liquete, C.; Vihervaara, P.; Schägner, J.P.; Grizzetti, B.; Drakou, E.; La Notte, A.; Zulian, G.; et al. Mapping ecosystem services for policy support and decision making in the European Union. Ecosyst. Serv. 2012, 1, 31-39. [CrossRef]

19. Mooney, P. A systematic approach to incorporating multiple ecosystem services in landscape planning and design. Landsc. J. 2014, 33, 141-171. [CrossRef]

20. Dickinson, D.C.; Hobbs, R.J. Cultural ecosystem services: Characteristics, challenges and lessons for urban green space research. Ecosyst. Serv. 2017, 25, 179-194. [CrossRef]

21. Schaich, H.; Bieling, C.; Plieninger, T. Linking Ecosystem Services with Cultural Landscape Research. GAIA Ecol. Perspect. Sci. Soc. 2010, 19, 269-277. [CrossRef]

22. Riechers, M.; Barkmann, J.; Tscharntke, T. Perceptions of cultural ecosystem services from urban green. Ecosyst. Serv. 2016, 17, 33-39. [CrossRef]

23. Lovell, S.; Johnston, D.M. Designing landscapes for performance based on emerging principles in landscape ecology. Ecol. Soc. 2009, 14, 44. [CrossRef]

24. Plieninger, T.; Bieling, C.; Fagerholm, N.; Byg, A.; Hartel, T.; Hurley, P.; López-Santiago, C.A.; Nagabhatla, N.; Oteros-Rozas, E.; Raymond, C.M.; et al. The role of cultural ecosystem services in landscape management and planning. Curr. Opin. Environ. Sustain. 2015, 14, 28-33. [CrossRef]

25. De Valck, J.; Landuyt, D.; Broekx, S.; Liekens, I.; De Nocker, L.; Vranken, L. Outdoor recreation in various landscapes: Which site characteristics really matter? Land Use Policy 2017, 65, 186-197. [CrossRef]

26. Scholte, S.S.; van Teeffelen, A.J.; Verburg, P.H. Integrating socio-cultural perspectives into ecosystem service valuation: A review of concepts and methods. Ecol. Econ. 2015, 114 (Suppl. C), 67-78. [CrossRef]

27. Beck, A.C.; Campbell, D.; Shrives, P.J. Content analysis in environmental reporting research: Enrichment and rehearsal of the method in a British-German context. Br. Account. Rev. 2010, 42, 207-222. [CrossRef]

28. Shrivastava, R.; Mahajan, P. Artificial intelligence research in India: A scientometric analysis. Sci. Technol. Libr. 2016, 35, 136-151. [CrossRef]

29. Li, H.M.; Jin, Y.M. A Construction of Landscape Evaluation Indicator System for the Urban Comprehensive Park Based on the Theory about Three Elements. Appl. Mech. Mater. 2011, 99-100, 496-500. [CrossRef]

30. Bertram, C.; Rehdanz, K. Preferences for cultural urban ecosystem services: Comparing attitudes, perception, and use. Ecosyst. Serv. 2015, 12, 187-199. [CrossRef]

31. Campbell, L.K.; Svendsen, E.S.; Sonti, N.F.; Johnson, M.L. A social assessment of urban parkland: Analyzing park use and meaning to inform management and resilience planning. Environ. Sci. Policy 2016, 62, 34-44. [CrossRef]

32. Chiesura, A. The role of urban parks for the sustainable city. Landsc. Urban Plan. 2004, 68, 129-138. [CrossRef]

33. Hegetschweiler, K.T.; de Vries, S.; Arnberger, A.; Bell, S.; Brennan, M.; Siter, N.; Olafsson, A.S.; Voigt, A.; Hunziker, M. Linking demand and supply factors in identifying cultural ecosystem services of urban green infrastructures: A review of European studies. Urban For. Urban Green. 2017, 21, 48-59. [CrossRef]

34. Thompson, I. Aesthetic, social and ecological values in landscape architecture: A discourse analysis. Ethics Place Environ. 2000, 3, 269-287. [CrossRef]

35. Jiang, W. Ecosystem services research in China: A critical review. Ecosyst. Serv. 2017, 26, 10-16. [CrossRef]

36. Costanza, R.; De Groot, R.; Braat, L.; Kubiszewski, I.; Fioramonti, L.; Sutton, P.; Farber, S.; Grasso, M. Twenty years of ecosystem services: How far have we come and how far do we still need to go? Ecosyst. Serv. 2017, 28, 1-16. [CrossRef] 
37. Czúcz, B.; Arany, I.; Potschin-Young, M.; Bereczki, K.; Kertész, M.; Kiss, M.; Aszalós, R.; Haines-Young, R. Where concepts meet the real world: A systematic review of ecosystem service indicators and their classification using CICES. Ecosyst. Serv. 2018, 29, 145-157. [CrossRef]

38. Schröter, M.; Van Der Zanden, E.H.; van Oudenhoven, A.; Remme, R.; Serna-Chavez, H.M.; De Groot, R.S.; Opdam, P. Ecosystem services as a contested concept: A synthesis of critique and counter-arguments. Conserv. Lett. 2014, 7, 514-523. [CrossRef]

39. Lam, S.T.; Conway, T.M. Ecosystem services in urban land use planning policies: A case study of Ontario municipalities. Land Use Policy 2018, 77, 641-651. [CrossRef]

40. Peavey, E.; Vander Wyst, K.B. Evidence-based design and research-informed design: What's the difference? Conceptual definitions and comparative analysis. HERD Health Environ. Res. Des. J. 2017, 10, 143-156. [CrossRef]

41. Hirons, M.; Comberti, C.; Dunford, R. Valuing Cultural Ecosystem Services. Annu. Rev. Environ. Resour. 2016, 41, 545-574. [CrossRef]

42. Spangenberg, J.H.; Settele, J. Precisely incorrect? Monetising the value of ecosystem services. Ecol. Complex. 2010, 7, 327-337. [CrossRef]

43. Kupschus, S.; Schratzberger, M.; Righton, D. Practical implementation of ecosystem monitoring for the ecosystem approach to management. J. Appl. Ecol. 2016, 53, 1236-1247. [CrossRef]

44. Brown, G.; Hausner, V.H. An empirical analysis of cultural ecosystem values in coastal landscapes. Ocean Coast. Manag. 2017, 142, 49-60. [CrossRef]

45. Bryan, B.A.; Raymond, C.M.; Crossman, N.; MacDonald, D.H. Targeting the management of ecosystem services based on social values: Where, what, and how? Landsc. Urban Plan. 2010, 97, 111-122. [CrossRef]

46. Plieninger, T.; Dijks, S.; Oteros-Rozas, E.; Bieling, C. Assessing, mapping, and quantifying cultural ecosystem services at community level. Land Use Policy 2013, 33, 118-129. [CrossRef]

47. Bieling, C.; Plieninger, T. Recording Manifestations of Cultural Ecosystem Services in the Landscape. Landsc. Res. 2013, 38, 649-667. [CrossRef]

48. Christie, M.; Fazey, I.; Cooper, R.; Hyde, T.; Kenter, J.O. An evaluation of monetary and non-monetary techniques for assessing the importance of biodiversity and ecosystem services to people in countries with developing economies. Ecol. Econ. 2012, 83, 67-78. [CrossRef] 